\title{
Comparison of Research and Application of Private University Teacher Motivation at Home and Abroad
}

\author{
Han meifeng ${ }^{1, a, ~}{ }^{*}$, Wang $\mathrm{Li}^{1, \mathrm{~b}}$ and Cao Ying ${ }^{1, \mathrm{c}}$ \\ ${ }^{1}$ No.999-26 Bingang road, Lvshun development zone, Dalian city, Liaoning province, China 116052

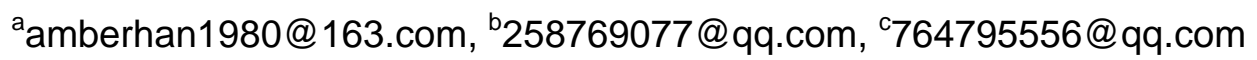

${ }^{*}$ Corresponding author

Keywords: private colleges and universities, teachers, motivation.

\begin{abstract}
China's private colleges and universities resumed their running in the 1970s, and have been developing for more than 30 years. They have gradually developed into a force that cannot be ignored in China's higher education cause. For private higher education to seek for further development and breakthrough, the construction of its own teacher team will be a topic that cannot be ignored. Based on the perspective of private higher education teacher motivation, this paper makes a comparative analysis of the current research status and practical application status at home and abroad. This paper first expounds the theoretical research and practical application of private college teacher motivation in foreign countries, then expounds the research status and practical application in China, and finally compares and briefly evaluates the domestic and foreign research and practical application of private college teacher motivation.On the one hand, it describes the value of the research and practical application of private university teachers' motivation at home and abroad; on the other hand, it points out the shortcomings of related research and the necessity and direction of further research.
\end{abstract}

\section{Introduction}

Throughout the development of education, private capital has a long history. At present, most of the internationally renowned universities are private ones. In the United States, the top 20 are private. The same is true in Britain, Australia, Japan and Singapore, where private universities generally have a higher reputation than public ones. Both students seeking employment and education workers prefer private universities. Therefore, in the future, the education system in China will change dramatically under the general trend of the change of international education pattern. The research on the encouragement of private college teachers is of great significance to the construction of private college teachers. This paper hopes to provide some useful references for the development of private colleges and universities in China through the comparative research on the motivation of private colleges and universities at home and abroad.

\section{Overseas research status}

The study of motivation in foreign countries deepens with the researchers' deep understanding of human nature. There are many relevant theories about motivation: hierarchy of needs, two-factor theory, expectation theory, reinforcement theory, Potter Borough comprehensive excitation model and so on. The research and exploration of university teachers' motivation also develops and continues to deepen.

In addition, the development of research on teacher motivation in colleges and universities is closely related to the development of modern university philosophy. The research started from John Henry Newman's research on teacher motivation based on classical management thoughts. He advocated the survival and development of higher education. After that, a series of relevant theoretical developments have emerged. For example, the research of American sociologist Veblen focuses on the study of teachers' income and working conditions, the relationship between teachers and other members of the school, and the role of "justice" in teacher motivation. Humboldt believed that the absoluteness of university scientific research and encouraged the government not to interfere 
in academic freedom, thus stimulating teachers to devote themselves to teaching and scientific research [1]. After the 20th century, with the further development of the motivation theory, the research on the motivation of university teachers has become more and more in-depth, which includes the following aspects.

\subsection{Research on influencing factors of teachers' satisfaction and work enthusiasm}

As for the research on the factors influencing teacher satisfaction, the famous scholar Smith Kendall \& Hurin, after a large amount of research and comparative analysis, believes that managers, job content, work companions, promotion space and salary are the five factors influencing teacher satisfaction. In addition, management scholar Craig has drawn similar conclusions. Financial aid, teacher professional development, students' progress and school recognition are key factors for teachers to improve their performance and enhance their job satisfaction.In addition, there are two factors that are particularly important and feasible in terms of improving teachers' love for higher education work and reducing the loss of high-quality education resources, namely, improving teachers' social status and enhancing their professional degree.

As for the factors influencing teachers' work enthusiasm, psychologist Mark Hansen pointed out that there are mainly three motives for teachers to actively participate in work. Working conditions and working environment; The third point is the individual factor, namely the teacher's own personality characteristics and self-driven characteristics [2]. Through the research, it is found that cooperation and mutual learning can stimulate teachers' work enthusiasm and promote teachers to constantly improve their own ability and professional level. According to the famous management scholar Sergiovanni, the greatest motivation of teachers is moral motivation. If the university can create a common learning system and working atmosphere for teachers, it will have a significant incentive effect on teachers. In addition, some management experts believe that the personal potential of university teachers should not be neglected, and the incentive system should pay attention to the development of teachers themselves rather than blindly emphasizing some external requirements, such as job performance and academic achievements. If a teacher's sense of self-efficacy is low, it will lead to a sharp decline in his enthusiasm for learning, teaching and scientific research, etc. However, excessive work pressure and work intensity will also easily cause a loss of confidence in his work and a loss of his demission [3].

\subsection{Research on salary incentive of college teachers}

In the research of teacher incentive mechanism, many researchers regard salary incentive as an important part. Firstly, Beaumont summarized the salary system of American college teachers into three types: First, the contract salary system, which is generally considered as performance salary; Second, the hierarchical wage system; Third, non-traditional salary system. These include merit pay and grade pay. Beaumont argues that merit pay is the dominant incentive in American universities. In addition, American universities generally adopt the annual salary system. The annual salary will be increased every year or every two years. The automatic growth part is generally enjoyed by everyone, and the incentive growth part is the reward for teachers to achieve good teaching results and obtain remarkable scientific and academic achievements [4].

Professor William James of Harvard University, who has conducted extensive data surveys and comparative analysis, found that when time is used to calculate compensation, employees can generally use only 20 to 30 percent of their individual potential to avoid being fired, but when they are sufficiently motivated, their abilities can reach 80 to 90 percent. Therefore, the proportion of incentive compensation should be increased in the design of compensation. A survey of college teacher pay between 1987 and 1995 found that for every \$1,000 increase in pay in Texas, the rate of teacher attrition and career change decreased by 2.9 percent, while it decreased by 5 to 6 percent among Hispanic and black teachers. A 1\% increase in wages in other industries has led to 2.11\% of teachers switching careers, according to Climan and Parker. To sum up, as in other industries, salary is a key issue that cannot be ignored in the research of teacher motivation, and is one of the most influential factors in satisfaction and work enthusiasm. However, the improvement of teachers' salary 
level is only one of the means to solve the incentive problem. The role of salary cannot be over exaggerated, and all problems can be solved by improving the treatment of teachers, and the influence of other factors on teachers' satisfaction and work enthusiasm cannot be ignored [5].

\subsection{Evaluation and incentive research}

In terms of evaluation and motivation research, Baryghadar of the United States pointed out that it is necessary to limit teachers' teaching workload, which on the one hand can better guarantee the teaching effect, and on the other hand can help teachers to invest time and energy in teaching, scientific research and service in a balanced way. For teachers with a certain term of office, the evaluation before the expiry is very strict, the decision whether to renew the appointment of teachers, whether to switch to tenure. At the same time, the result of this evaluation mechanism will also affect the salary and honor of teachers. In terms of students' evaluation of teachers, the credit system is widely adopted in American universities, and students choose courses independently. The teacher's class performance, knowledge reserve level and the image in students' mind are the key factors for students to consider when choosing courses. The course cannot be opened if the number of students in the subject is less than the prescribed number. This teacher should be dismissed completely. In addition, colleges and universities will let students evaluate teachers' work attitude, teaching quality and teaching effect in an anonymous way, which truly reflects the student-centered approach. In academic evaluation, the evaluation of professional peers is extremely important, and the peer evaluation of professional academic achievements is more authoritative. Therefore, peer expert evaluation is widely used in academic evaluation in American universities [6,7].

\section{Domestic research status}

\subsection{Theoretical research}

In China, the research on incentive theory started relatively late, but the achievements are also comparatively rich, among which the representative achievements are synchronous incentive theory and comprehensive incentive theory. Synchronous excitation theory is proposed by professor $\mathrm{Yu}$ Wenzhao in combination with China's national conditions and features of education. He believes that only when the material and spiritual motivation is implemented organically, comprehensively and synchronously according to the natural and social needs of human beings can better incentive effect be achieved. The comprehensive incentive theory was put forward by professor Xiong Chuanwu on the basis of absorbing the excellent research results of the foreign incentive theory. He believes that in an incentive system, motivation includes at least three elements: one is the person, that is, the subject and object of motivation. Second, space-time, that is the process of excitation and the corresponding environment. Third, mode and content. To deal with the relationship of these factors, it involves the "overall motivation" composed of the whole staff, the whole process and the whole elements.

In addition, some domestic scholars also analyze the needs of teachers based on the hierarchy of needs theory. Two factors theory was used to analyze teacher motivation problems such as teacher satisfaction.Using the theory of achievement motivation, this paper proposes to enhance the teacher's personal value and sense of achievement by finding the source of the teacher's sense of achievement $[8,9]$.

\subsection{Application research}

Some domestic scholars also made a targeted analysis of the incentive measures of colleges and universities, found problems and deficiencies, and provided measures and methods to improve the incentive mechanism. This kind of exploration is based on field investigation, and the insufficiency of existing mechanism is explored, and corresponding research conclusions are drawn. For example, Zeng Chun pointed out in a research document in 2005 that the implementation process of the incentive system of colleges and universities has serious problems, such as the unscientific setting of 
incentive measures, adherence to the rules and regulations of the old system, and failure to keep pace with the Times. These problems become the constraint factors in the development of colleges and universities and restrict the reform and innovation of colleges and universities. From the perspective of human resource allocation mechanism such as teacher appointment system and post allowance distribution, scholars such as Zhang Ling and Shi Ou discussed the key factors influencing teachers' teaching initiative. Wang Hui carried out the research by combining the professional characteristics and demand characteristics of university teachers. Researchers such as Ding ke and Yin Xuejiao pointed out that the construction of effective incentive mechanism in colleges and universities can optimize the teacher structure and stabilize the teacher team. Ho Zhian points out that the significance of improving university teacher motivation lies in effectively meeting the needs of teachers, strengthening their role awareness and behavior, and stimulating their creativity and subjective initiative [10].

In terms of the countermeasures and Suggestions for the improvement of teacher motivation in colleges and universities, Ding Hao and Wang Meitian suggest to design a salary incentive mechanism that can meet the mutual support of teacher participation, restriction and incentive. Design differential incentive contracts. Promotion plays a key role in teacher motivation. As an intangible asset, the reputation of teachers should be paid full attention to. On the construction of private education teacher incentive mechanism, Gao $\mathrm{Yu}$, a scholar, suggested that: first, the consistency of teachers' personal goals and organizational goals should be ensured, and the sense of honor, mission and responsibility should become the main theme of teachers' career life. Secondly, the policy making of private colleges and universities should maintain good continuity and consistency, so as to effectively mobilize and give play to teachers' potential energy and creativity. Third, to ensure fairness, reasonableness and transparency; Fourth, we should pay attention to leniency and severity, and give priority to positive motivation to ensure the organizational atmosphere is full of vitality and positive energy.

\section{Summary}

To sum up, both at home and abroad, research of teacher motivation in public or private colleges and universities should be comprehensive analysis of the characteristics of the incentive object, accurately find the effective incentives and reasonable incentives, can achieve more ideal incentive effect. On the basis of critically absorbing the western incentive theory and combining with China's national conditions, domestic scholars have made more in-depth exploration of the research on the incentive mechanism of college teachers under the special background of China, and have also obtained abundant research results. Domestic researchers have stronger pertinence on the research of teacher incentive mechanism, such as specific methods, assessment contents and procedures of teacher appointment, etc., which are mostly living examples in the construction of school teacher team, and have pertinence and practicability.

In addition, these studies also have some shortcomings. First, foreign studies on teacher incentive are mature and rich, but they are not completely suitable for China's specific national conditions. Secondly, the discussion on how to encourage college teachers to devote more energy and enthusiasm to teaching and scientific research is relatively limited. In recent years, both the department in charge of education and the school itself begin to "return" to the origin of higher education, teaching still needs to be the most basic responsibility and mission of teachers. In addition, domestic researchers on teacher motivation are mostly managers or teachers of education public universities, and there is a great space for further research on teacher motivation in private universities. Private education has a short history in China and is still a new topic. There is still a long way to go in the research on the incentive mechanism of private colleges and universities. Its theory and practice still need to be further studied. 


\section{Acknowledgements}

Project NO. : LMJK2017072, International Comparative Study on the Construction of Private Applied Technology Universities, Liaoning Provincial Private Education Association Project, 2017

\section{References}

[1] Xie Wei, Analysis of the Development Status of Incentive Mechanism for Domestic and Foreign University Teachers , J. Realistic. vol.02, pp. 16-18, 2004.

[2] Redman T. and Wilkinson A, Contemporary Human Resource Management Text and Cases, J. Prentice Hall, 2001.

[3] Wang Yuhui, Comparative Study on the Similarities and Differences Between the Appointment System of Teachers in China and the United States ,J. Navigation Education Study, vol. 03, pp. 34-35, 2004.

[4] Gan Xiaoya, Research on Incentive Mechanism of University Teachers, D. Wuhan University, pp. 35-37, 2005.

[5] Yang Changqing, Research on the Evaluation of College Teachers from the Perspective of Yardstick and Motivation of the Ivory Tower, M. Southeast University Press, 2012.

[6] Yu Wenzhao, Incentive Theory and Its Model in China, M. East China Normal University Press, 1993.

[7] Xiong Chuanwu, School Management Psychology, M. East China Normal University Press, 1996.

[8] Guo Jing, Research on Incentive Strategies for University Teachers Based on the Analysis of Hierarchy of Needs, J. Human Resource Management, vol. 06, pp. 39-41, 2010.

[9] Li aixia, A Study on the Motivation of Teachers in Private Universities in China Based on the Two-factor Theory, J. Science and Technology Intelligence Development and Economy, vol. 08, pp. 16-18, 2010.

[10]Qi Xianjun, Inspiration of American University Incentive Mechanism to China's University Construction, J. Anyang Institute of Technology, vol. 08, pp. 19-20, 2006. 